\title{
sciendo
}

Research Article

(C) 2019 Nurkhamitov et.al.. This is an open access article licensed under the Creative Commons Attribution-NonCommercial-NoDerivs License (http://creativecommons.org/licenses/by-nc-nd/3.0/).

\section{Special Aspects of Military and Political Euphemisms Usage in Modern English Press}

\author{
Marsel Radikovich Nurkhamitov \\ Elena Nikolaevna Zagladina \\ Irina Zinov'evna Shakhnina \\ Kazan Federal University, \\ Institute of International Relations, \\ History and Oriental Studies
}

Doi: 10.2478/ajis-2019-0019

\begin{abstract}
The given article is dedicated to consideration of military euphemisms used by the English language print media to describe various conflict-ridden actions in the course of military developments across the globe. Significance of the given research is stipulated by the vivid interest to the matters of euphemy penetrated into all areas of activity, especially in mass media language style. The aim of this paper is to examine the concept and the essence of euphemy and to reveal various military-political euphemisms widely used in press. Methods used to study the subject of the given paper were as follows: theoretical literature study within the given theme, a descriptive method, followed by the method of sampling euphemisms from Anglophone print media. The main result of the present study appears to be the finding, that euphemization presents a significant process of enormous importance in communication. The usage of euphemistical examples in the contemporary English-speaking press, namely, the New York Times, the Sun, the Telegraph, the Wall Street Journal and the Washington Post served as the main data for the given research.
\end{abstract}

Kaywords: linguistics, discourse, stylistics, euphemisms, military euphemisms, media language, English press

\section{Introduction}

Linguistics today has a high demand in highlighting various military, international and inter-ethnic conflicts in the language of mass media which take on enormous importance in the life of the contemporary society. In the XXI century mass media steps forward as the most intensely developing side of the oral activity in the society. The stylistically neutral "unmarked" words and expressions are used in the contemporary language more and more frequently instead of a synonymous language unit which a speaker considers to be rude, unacceptable or indelicate. Such process is called "euphemization" in the contemporary linguistic literature.

The present-day printing editions reflect all the events happening not only in one country but worldwide. The print media act as a specific catalyst element since lexical formatives of different levels find their way to standard language and the oral speech. Texts from newspapers and magazines present a highly interesting material for various linguistic studies. Euphemisms usage in the contemporary Anglophone press can be determined as a vivid example of such phenomenon. 


\section{Methods}

The methodology of the research approaches makes possible to expand the sufficient insight into the core of the given linguistic phenomenon of euphemism and to understand its enormous significance for the mass media style. Consideration of the theoretical and special linguistic literature within the theme is the leading method for these studies. Analysis of the theoretical and linguistic literature of different scientists on this theme has revealed that euphemia presents a complex linguistic phenomenon. The areas of euphemisms usage refer to the age, mental and physical ability, appearance, race and ethnicity, social and financial standing, profession, diplomacy and military issues.

\section{Results}

Analysis of the theoretical and linguistic literature on this theme has revealed that euphemia presents a complex linguistic phenomenon. The areas of euphemisms usage refer to the age, mental and physical ability, appearance, race and ethnicity, social and financial standing, profession, diplomacy and military issues. War has a great impact on the whole world and, at the same time, turns to be an up-to-date sphere for new euphemisms creation. Governments are in want of euphemisms to make the folk put up easier with the war hardships and consequences. In the context of the present-day verbal and information wars it is possible to call things as they are solely for deterrence of the opposing side.

One might say that military discourse euphemisms possess a high variability and can be divided into several lexical sets:

1. Euphemisms describing the course of war operations.

2. Euphemisms designating battle injuries and diseases received in the course of war actions.

3. Euphemisms camouflaging the army's negative actions.

4. Euphemisms displacing genuine designations of different weapons or arms type.

5. Euphemisms associated with terrorism.

6. Euphemisms designating slaughter and death.

7. Euphemisms characterizing the war actions participants.

8. Euphemisms designating auxiliary devices and institutions employed for military purposes.

9. Euphemisms associated with nuclear weapons subject matter.

10. Euphemisms eliminating different types of discrimination.

The analysis of such Anglophone printing editions as the New York Times, the Sun, the Telegraph, the Wall Street Journal and the Washington Post has manifested the following examples of military euphemisms:

1. British military operations in Iraq will finally end today, eight years after the US invasion... [The Sunday Times - British military operations in Iraq end today].

2. The Indian press refers to the Mig 21 as the Flying Coffin, but they are all flying coffins or cremation discs for the IAF pilots. [Rupee News - World record: 500th Indian "Flying Coffin" Mig crashes. The IAF has the worst crash record on the planet].

3. "The Taliban remains a force to be reckoned with, determined to reestablish its power base in Afghanistan" [The forgotten war (01 Okt 2012)/The Telegraph]. The word combination "to reestablish its power base" means "to invade" in simple terms. This euphemism shows the aspiration to hide opposing side's aggressive intentions as well as to extenuate the current reality.

4. "It shows it's not just lads from council estates putting their lives on the line for this country" [Harry's staying put ... he won't run from the Taliban (16 Sept 2012)/ The Sun]. The expression "to put their lives" is used to substitute the verb "to die".

5. Israel fears that if Syrian President Bashar Assad's regime is toppled, the country could fall into the hands of Islamic extremists or descend into sectarian warfare, destabilizing the region [Israel fires at Syria for first time after mortar strikes military base (11 Nov 2012)/ The Washington Post]. The phrase "can fall into the hands of Islamic extremists" is 
used instead of the word combination "Islamic extremists can get hold Syria".

6. The clashes have threatened to draw the two sides into a major confrontation two months before Israeli elections, a possibility underlined by Prime Minister Benjamin Netanyahu's warning that Israel was ready to strike harder against the militants if the violence persisted [Israel, Gaza Militants Trade Fire in Escalation (11 Nov 2012)/ The Wall Street Journal].

Such nouns as "the clashes" and "the confrontation" turned out to be the more frequently used euphemisms for "warfare".

7. The admission is the most serious warning yet that Britain is preparing for some sort of military involvement in the country [Britain could intervene militarily in Syria in months, UK's top general suggests (11 Nov 2012)/ The Telegraph].

In this case the euphemistical expression "some sort of military involvement" is designed to more directly denote "to break in".

8. Such denominations existed in military verbiage long ago and were invoked to hide the full tenor of the messages being conveyed, e.g., "a party" in the meaning of "a battle".

9. Euphemistical expressions in mass media are most often used to denominate the bodies of power and their activities: "persuasion" instead of "torture", - quite politically correct phrase to avoid the disaffected people's negative evaluations.

10. Euphemism examples associated with arms manufacturing are as follows: "special materials" instead of "enriched uranium and plutonium" (that is "enriched uranium and plutonium for bomb manufacturing").

11. Euphemistical expressions used in mass media to designate the notion "nuclear bomb": device, unit, special weapon, modern weapon.

\section{Discussion}

Euphemism corresponds to a complicated linguistic phenomenon having been in the focus of the researchers' attention for a long time. Euphemization issues have found their rightful place in the works of such domestic and foreign linguists as O.S. Akhmanova, K. Burrige, S. Vidlak, H. P. Grice, R. Holder, J. Neaman, B.A. Larin, G, Paul, A.A Reformatski, D.E. Rosental, D.N. Shmelyov, L.V. Shcherba, etc. Nowadays the research community presented by L.V. Artyushkina, N.M. Berdova, Zh. Zh. Varbot, A.M. Katsev, M.L. Kovshova, L.P. Krysin, V.P. Moskvin, E. P. Senichkina, E.I. Sheigal, etc., actively works at euphemization issues. Linguistic writings contain multiple definitions of the notion "euphemy". In A.A Reformatski's view, "Euphemisms are substituted permitted words used instead of prohibited (taboo) ones" [Reformatski, 1967]. Encyclopedia "Krugosvet" gives the following definition: "Euphemism (from Greek words "good" and "speak") is a stylistically neutral word or expression employed instead of a synonymous language unit which seems to be rude, indelicate or obscene to a speaker. Thus, euphemisms most often mask or camouflage the core of the phenomenon". According to the English linguists, a substantial proportion of vocabulary and phraseology of the English language can be attributed to euphemisms. In N.S. Arapova's judgement, euphemisms are the emotionally neutral words which substitute synonymous ones sounding to a speaker as improper, unbecoming, inappropriate or indelicate. Euphemism also appears to be occasional conformity or contextual replacement substituting one word for another as well as camouflaging the true nature of the signified. [Arapova, 2000; Shirvani et al, 2015; Murasheva et al, 2018].

According to Toroptseva, euphemistic nature of the statement implies creation of a positive or neutral connotation in contradiction to a negative connotation of a substituted word: "Euphemisms are neutrally or positively connoted designations that define stigmatic denotations and/or replace negatively connoted naming units" [Toroptseva, 2003]. As British and American lexicographers put it, euphemisms also comprise various jargon words, vulgarisms, technical terms and slangy words. Thus, J.Neaman and K.Silver add slangisms and jargonisms into their Dictionary of euphemisms drawing on the fact that words and expressions belonging to a limited professional or social group exercise the function of camouflaging undesirable subject for the majority of the native speakers [Neaman and Silver, 1983; Etcuban \& Pantinople, 2018] . S.G. Ter-Minasova considers that the 
concept "political correctness" implies substitution of politically incorrect terms for "the appropriate neutral or positive euphemisms" [Ter- Minasova, 2000]. The authors believe that in some cases the language speakers perceive vulgarisms as less offensive or rude words than direct ordinary naming units. The authors call such lexical units as "vulgar euphemisms", e.g. "bums", "knocker" [Enright, 1985].

Nevertheless, the lexicographers suggest no clear separation between the notions "euphemy", "jargon" and "slang". S.G. Ter-Minasova considers political correctness of language to be a powerful cultural and behavioral as well as linguistic tendency revealing itself in the attempt to look for the new ways of language expression instead of those able to hurt a person's feelings or dignity, restrict the rights by habitual language discourtesy and/or undiplomatic remarks in relation to age, social status, race or sex, appearance, etc. In Russia the term "political correctness" came in use comparatively not so long ago, though the idea itself appeared in the USA at the close of XX century. It is hard to detect the exact date when the notion "political correctness" emerged, so it remains to be a disputable problem. It is commonly believed that primarily the term was introduced by Karen de Crow, President of the National Organization for Women's Right Protection, in 1975. At first, political correctness as the belief system spread throughout all American educational institutions but later it penetrated into all spheres of the American society. Subsequently this concept was practiced on a wide scale by television and in the columns of all newspapers. [Shemshurenko, 2013; Ardakani et al, 2015].

In this regard R.A. Spears' dictionary "Slang and Euphemism", though debatable in its content, is quite indicative [Spears, 2001]. R. Holder presents his own subject classification where he distinguishes 68 lexical and semantic groups of euphemisms. For instance, "Warfare" "Politics", "Age", "Illness and Injury", "Cheating", "Police", "Boasting and Flattery", etc. This classification makes possible to determine more precisely the spheres of euphemistical lexic demonstrating the abundance and multiple aspect nature of stigmatic denotata group being designated by euphemisms. R. Holder voices the opinion that attributing one or another word/expression to euphemism is quite subjective and experience based.

\section{Summary}

The phenomenon of euphemy is inextricably bound up with the political correctness theory. The political correctness of the language is defined as a powerful cultural and behavioral as well as a linguistic tendency revealing itself in the attempt to look for the new ways of language expression instead of those able to hurt a person's feelings or dignity, restrict the rights by habitual language discourtesy and/or undiplomatic remarks in relation to age, social status, race or sex, appearance, etc.

\section{Conclusions}

On the basis of all the above-stated we conclude that euphemism turns up to be rather complicated social, psychological and linguistic phenomenon representing the integral universal component of the communication process in contemporary languages and culture and taking on the role of the main means of successful personal interaction. Whereas euphemism is a neutral, mitigating word or phrase displacing a taboo word. Main reasons of euphemisms employment are aspiration to avoid conflicts in interpersonal communication as well as veiling the essence of matter. The phenomenon of euphemy is inextricably bound up with the political correctness theory. The political correctness of the language is defined as a powerful cultural and behavioral as well as a linguistic tendency revealing itself in the attempt to look for the new ways of language expression instead of those able to hurt a person's feelings or dignity, restrict the rights by habitual language discourtesy and/or undiplomatic remarks in relation to age, social status, race or sex, appearance, etc. Euphemization is claimed to be one of the peculiarities intrinsic to mass media language. That is why modern Anglophone printing editions are replete with a great number of euphemisms. In our time euphemization is instrumental in building up good public opinion at mass media coverage of military operations. Apart from everything else, military-political euphemisms appear to be an 
integral part of any language and play a significant role in the process of informational influence on the human consciousness.

\section{Acknowledgements}

The work is performed according to the Russian Government Program of Competitive Growth of Kazan Federal University.

\section{References}

Arapova, N.S. (2000). "Euphemisms", Language Study, BES. - M: Big Russian Encyclopedia, p. 590.

Ardakani, M. P., Lashkarian, A., \& Sadeghzadeh, M. (2015). The Translatability/Untranslatability of Poetics: Eliot's" Ash Wednesday" and its two Persian translations. UCT Journal of Social Sciences and Humanities Research, 3(1), 52- 60.

Enright, D.J. (1985). "Fair of Speech: The Uses of Euphemism"., Oxford University Press.

Etcuban, J. O., \& Pantinople, L. D. (2018). The Effects of Mobile Application in Teaching High School Mathematics. International Electronic Journal of Mathematics Education, 13(3), 249-259. https://doi.org/10.12973/iejme/3906

Holder, R.W. (2003). "A Dictionary of Euphemisms. How not to Say What You Mean", Oxford University Press Inc., New York.

Khasanova, N.F. Fakhrutdinova A.V., (2016). "Grammatical means of creating expressivity in English press language", International Journal of Humanities and Cultural Studies ISSN 2356-5926., Special Issue July, pp. $348-354$.

Murasheva, A. A., Stolyarov, V. M., Lomakin, G. V., Lepekhin, P. A., \& Tarbaev, V. A. (2018). Evaluate the use of farmlands encumbered with electric grid facilities: damage factors and solution approaches. Opción, 34(85-2), 677-705.

Neaman, J.S. (1995). "The Wordsworth Book of Euphemism"., London: Wordsworth Editions LTD. p. 310.

Neaman, J.S. Silver, C.G. (1983). "Kind Words: A Thesaurus of Euphemism": New York.

Reformatski, A.A. (1967). 'Introduction to Linguistics'. - M: MGU, p. 99.

Shemshurenko, O. V. (2013). "Euphemisms from the perspective of political correctness theory (as exemplified in American printing editions of the XXI century)", Philology and Culture, №. 4 (34), p. 144-151.

Shirvani, M., Mohammadi, A., \& Shirvani, F. (2015). Comparative study of cultural and social factors affecting urban and rural women's Burnout in Shahrekord Township. UCT Journal of Management and Accounting Studies, 3(1), 1-4.

Spears, R.A. (2001). "Slang and Euphemism: A Dictionary of Oaths, Curses, Insults, Ethnic Slurs, Sexual Slang and Metaphor, College Lingo and Related Matters, Signet. 2001.

Ter- Minasova, S.G. (2000). "Language and Intercultural Communication”, M: Slovo, p. 624.

Toroptseva, E.N. (2003). "Euphemistical denominations in the aspects of language, history and culture", Dissertation. Candidate of Philological Sciences, M: p. 193. 